$\frac{\text { DE }}{G}$ DE GRUYTER

\title{
VALUABLE COMPONENTS OF DRIED POMACES OF CHOKEBERRY, BLACK CURRANT, STRAWBERRY, APPLE AND CARROT AS A SOURCE OF NATURAL ANTIOXIDANTS AND NUTRACEUTICALS IN THE ANIMAL DIET*
}

\author{
Marek Pieszka ${ }^{1}$, Piotr Gogol$^{2}$, Mariusz Pietras ${ }^{1}$, Magdalena Pieszka $^{3}$ \\ ${ }^{1}$ Department of Animal Nutrition and Feed Science, National Research Institute of Animal Production, \\ 32-083 Balice n. Kraków, Poland \\ ${ }^{2}$ Department of Biotechnology of Animal Reproduction, \\ National Research Institute of Animal Production, 32-083 Balice n. Kraków, Poland \\ ${ }^{3}$ Department of Horse Breeding, Agricultural University, Al. Mickiewicza 24-28, 30-059 Kraków, \\ Poland \\ •Corresponding author: marek.pieszka@izoo.krakow.pl
}

\begin{abstract}
The chemical analysis of dried pomace of chokeberry, apple, black currant, strawberries and carrot was performed to determine the composition and content of nutrients and bioactive substances, among others the content of vitamins, phenolic acids, anthocyanins, and essential fatty acids. The antioxidant properties were determined in the extracts of pomace by determining the total antioxidant potential (TRAP) and antioxidant activity against DPPH radical. Tested pomaces contained $12-15 \%$ protein, approximately $18-20 \%$ crude fibre, approximately $2.7-4.0 \%$ ether extract and $1.8-3.0 \%$ ash. The highest level of anthocyanins was found in chokeberry pomace, followed by black currant pomace and several times less in strawberries and apples. The content of phenolic acids ranged from $12.91 \mathrm{mg} / 100 \mathrm{~g}$ in black currants to $630.30 \mathrm{mg} / 100 \mathrm{~g}$ in dried chokeberries. In terms of vitamins the richest source of vitamin $E$ was chokeberry pomace (152.3 mg/100 g), while most of the carotenoids were found in dried carrot $(15.35 \mathrm{mg} / 100 \mathrm{~g})$. The chain of antioxidant activity was as follows: black currant $>$ chokeberry $>$ apple $>$ strawberry $>$ carrot, while in terms of antioxidative capacity it was chokeberry $>$ apple>black currant $>$ strawberry $>$ carrot.
\end{abstract}

Key words: apple, chokeberry, strawberry, black currant, pomace, antioxidants

Fruit and vegetable pomaces produced as a byproduct during the production of juices can be an important and inexpensive feed additive for animals, but in our country they are only partially used in this way, mostly acting as troublesome waste. Poland is the leader in Europe in terms of production of fruit and vegetable juices,

*This research was realized within the project "BIOŻYWNOŚĆ - innowacyjne, funkcjonalne produkty pochodzenia zwierzęcego" (BIOFOOD - innovative, functional products of animal origin) no. POIG.01.01.02-014-090/09 co-financed by the European Union from the European Regional Development Fund within the Innovative Economy Operational Programme 2007-2013. 
and juices and juice drinks are the most important segment of the fruit and vegetable processing in our country (Nosecka, 2005). This fact determines the great economic importance of this problem. Seasonality of by-production of pomaces makes their direct utilization as feed for animals quite difficult, because it requires the inconvenient protection against unfavorable changes involving microorganisms. Therefore, an important means of pomace fixation for further processing is their drying. Depending on the type of material obtained pomaces only partly are used in food processing: either directly as a dried fruit or vegetable pomaces, or in further processing to obtain pectin, vitamins, polyphenols, and in the production of fruit teas, fruit distillates, flavors and food pigments. In addition, there are other ways of developing them by the industry on a small scale - for the purpose of producing oils, citric acid, alcohols and furfural, and even the use of seed fruit as cleaning and polishing rags. In view of the large scale of pomace production it seems appropriate to preserve them in the dried form and then use them as feed additives for animals. It can be expected that the drying pomaces will be characterized by a high content of biologically active substances and prebiotics, because they were prepared from the raw materials containing these substances, often in very large quantities. Just as fruits and vegetables, pomaces can be a very valuable source of natural antioxidants from the group of polyphenols - particularly anthocyanins and flavonoids, carotenoids, vitamin E and unsaturated fatty acids, as well as other vitamins and trace elements in animal diets. Fruits of chokeberry (Aronia melanocarpa) and black currant (Ribes nigrum) are known for high content of antioxidants from the anthocyanin group (Graversen et al., 2008), the fruit of apples (Malus domestica) contains admittedly less, but in the fruits of all three species other antioxidants from the group of polyphenols can be also found (Schieber et al., 2001; Kołodziejczyk et al., 2007). Carrot (Daucus carota) is known for its high content of beta-carotene and other carotenoids, which also exhibit antioxidant properties (Alasalvar et al., 2001).

The aim of the study was to determine the chemical composition and antioxidative properties of dried pomaces derived from pressing juice from chokeberries, strawberries, black currants, apples and carrots, as additives to animal feed that could enrich the diet in valuable bioactive components.

\section{Material and methods}

The study used dried pomace derived from pressing juice from chokeberries, strawberries, black currants, apples and carrots, obtained in 2011, courtesy of MegaSort Ltd. in Skrzyńsko.

\section{Reagents}

For all extractions and analysis the following reagents were used: ethyl acetate, acetone, methanol of gradient purity for HPLC Merck, 2,2-diphenyl-1-picrylhydrazyl (DPPH) Sigma-Aldrich. Deionized water was used for the analysis in Water System Deionizer MILLI-qPlus (Millipore, USA). Pure acetone (POCH Gliwice) and 
n-hexane (Sigma) were used for extractions of the samples and methanol of gradient purity for HPLC analysis (Merck). Tocopherols, carotenoids, phenolic compounds and fatty acids produced by Sigma-Aldrich, Fluka, and ICN were used as chromatographic standards.

\section{Analysis of the basic composition}

Basic composition of dried pomaces was determined by standard methods (AOAC, 1995). Mineral content was determined by atomic absorption spectrometry (AAS) on ICP-MS spectrophotometer after previous mineralization in a microwave oven Milestone Ethos Plus (Italy). Amino acid analysis was carried out on Amino Acid Analyzer AAA400 INGOS (Czech Republic) after prior hydrolysis. Integration of peaks was made using Chromulan program. The contents of all amino acids were determined by comparison with external standard and after taking into account the recovery. The level of detergent fiber fractions was determined by Goering and Van Soest method (1970).

\section{Spectrophotometric determination of the concentration of anthocyanins and carotene}

The sum of the anthocyanins and carotenoids were determined in extracts prepared separately, using the spectrophotometer JASCO V-530, in cuvettes of $0.5 \mathrm{~cm}$ and $1 \mathrm{~cm}$, obtaining spectrum in the visible light range. Anthocyanin extracts were made by homogenizing the samples of $1 \mathrm{~g}$ in triplicate, in a $1 \%$ solution of $\mathrm{HCl}$ in methanol. Anthocyanin concentration was calculated by determining the absorbance at $530 \mathrm{~nm}$ based on cyanidin glucoside, using the molar absorption coefficient of 29600. Extracts of carotenoids were made by homogenizing a sample of carotenoids of $1 \mathrm{~g}$ in triplicate with the addition of acetone portion, and then n-hexane. The sum of the carotenoids was determined using a JASCO V-530 spectrophotometer in $1 \mathrm{~cm}$ cuvettes obtaining the spectra of extracts from the dried samples, and setting the absorbance at $451 \mathrm{~nm}$. The concentration of the pigments was calculated by converting on the beta-carotene, based on the molar absorption coefficient of 139500 .

\section{Chromatographic determination of the concentration of phenolic com- pounds}

The determination of the phenolic compounds was made using gradient HPLC analysis on a Shimadzu LC-10AS chromatograph with a SPD-10AV detector, in a $250 \mathrm{~mm}$ LiChrospher 250mm RP18 $5 \mu \mathrm{m}$ column, in water-methanol system, with the addition of $\mathrm{H}_{3} \mathrm{PO}_{4}$ (Świderski et al., 2004). The extraction was carried out with $80 \%$ ethanol, conducting the material homogenization in porcelain mortar with the addition of silica sand. The extract was filtered through a glass frit into $20 \mathrm{~mL}$ volumetric flasks. The chromatograms were developed for summing the peak areas of the retention time intervals, every 5 minutes, allowing comparison of the differences in the content of each group of phenolic compounds: from simple monophenols to flavonoids and their glycosides. The appropriate fractions were converted to specific compounds of group of phenols analyzed as standards. 


\section{Chromatographic determination of vitamin $\mathbf{E}$}

Determination of vitamin E was performed by HPLC method based on the standard PN-EN ISO 6867-2002. Samples of dried pomaces were ground with Fritsch lab mill (Idar-Oberstein, Germany) with a sieve diameter of $0.80 \mathrm{~mm}$ and then weighed in an amount of $5 \mathrm{~g}$ with $0.01 \mathrm{~g}$ accuracy. The sample was saponified in the presence of potassium hydroxide and ethanol, and then vitamins were extracted with petroleum ether $\left(40-60^{\circ} \mathrm{C}\right)$. The solvents were removed by rotary evaporation. The residue was dissolved in ethanol. HPLC system produced by Merck-Hitachi (Darmstadt, Germany) equipped with L-7100 pump, L-7250 autosampler, FL L7485 detector system was used for the study. The data were integrated using the system HSM D-7000 LaChrom produced by Merck LaChrom-Hitachi (Darmstadt, Germany). Chromatographic separation was performed using reverse phase by chromatography column LiChroCART ${ }^{\mathrm{TM}}$ 250-4 Superspher ${ }^{\mathrm{TM}} 100$ RP-18 (4 micron) - Merck (Darmstadt, Germany) at room temperature. Methanol-water mixture $(96.5: 3.5$, v/v) was used as mobile phase using a flow rate of $1 \mathrm{~mL} / \mathrm{min}$. All injections were performed in $40 \mu \mathrm{l}$ using the "cut" method. The determination was performed at a wavelength of Ex. $295 \mathrm{~nm}$ and Em. $350 \mathrm{~nm}$. The internal standard addition method was used to determine the concentration of vitamin $\mathrm{E}$.

\section{Determination of fatty acids}

The fatty acid profile of the pomace samples was determined using gas chromatography. The analysis was based on the Folch method (1957), in which a $5.0 \mathrm{~g} \mathrm{sam-}$ ple was homogenized in a mixture of chloroform and methanol (v/v, 2/1), the solvent evaporated, and the evaporation residue saponified $(0.5 \mathrm{~N} \mathrm{NaOH}$ in methanol) and esterified ( $\mathrm{BF}_{3}$ in methanol). The fatty acid methyl esters produced were determined using gas chromatograph Varian 3400 equipped with FID detector, 8200 CX autosampler and Varian Star 4.5 software for the processing and calculation of chromatograms. Chromatographic separation was carried out by chromatograpic column CP Wax 58, $0.53 \mathrm{~mm}, 1 \mu \mathrm{m}$ (Chrompack, USA) using a temperature program: from $60^{\circ} \mathrm{C}$ to $188^{\circ} \mathrm{C}\left(4^{\circ} \mathrm{C} / \mathrm{min}\right)$, then to $220^{\circ} \mathrm{C}\left(5^{\circ} \mathrm{C} / \mathrm{min}\right)$. The temperature of the injector and FID detector: $200^{\circ} \mathrm{C}$ and $260^{\circ} \mathrm{C}$. Helium was used as a carrier gas $(6 \mathrm{~mL} / \mathrm{min})$. The hexane solutions of the samples were applied on the column at $1 \mu \mathrm{L}$.

\section{Chromatographic determination of the concentration of carotenoids}

Determination of carotenoids was performed by gradient HPLC analysis (MechNowak et al., 2012). Homogenizing of plant material and the extraction was performed first with the addition of acetone, and then continued with the addition of hexane, centrifuging the residue after extraction. Chromatographic separation was performed on a Shimadzu LC-10AS gas chromatograph with a SPD-10AV detector, column LiChrospher 125 RP18 produced by Merck (Darmstadt, Germany) with non-linear concentration gradient in water-methanol-hexane system at a flow of $1 \mathrm{~cm}^{3} / \mathrm{min}$.

\section{The total antioxidant potential (TRAP)}

The total antioxidant potential (TRAP) was evaluated using chemiluminescence as described by Lissi et al. (1995). Reaction mixture contained $20 \mu \mathrm{M}$ 2,2-azobis- 
(2-amidinopropane) (ABAP) and $100 \mu \mathrm{M}$ luminol in 0.1 M Tris buffer (pH 9.0) was used. Peroxyl radicals arising as a result of thermal decomposition of ABAP, in reaction with luminol has generated intense, stable chemiluminescence and its intensity was measured with the AutoLumat LB953 luminometer (Berthold, Germany). The addition of the sample extract $(20 \mu \mathrm{L})$ to the reaction mixture $(980 \mu \mathrm{L})$ resulted in a rapid decrease in the intensity of the chemiluminescence to the amount of time proportional to the amount of antioxidants in the sample. The wear of the antioxidants contained in the sample was followed by a rise in the emission of light, allowing the measurement of the induction time.

In our research, it was assumed that the induction time is the time required to return the intensity of chemiluminescence to achieve $10 \%$ of baseline value. The reference material was Trolox, which is a synthetic water-soluble analog of vitamin E with high antioxidant activity. On the basis of the induction time obtained for the sample $\left(\mathrm{t}_{\mathrm{s}}\right)$ and the induction time obtained for Trolox solution with a concentration of $5 \mu \mathrm{M}\left(\mathrm{t}_{\mathrm{t}}\right)$ the total antioxidant capacity of the sample expressed as microgram Trolox equivalent was calculated. The following formula was used: TRAP $\left.=\mathrm{f}_{\mathrm{s}} / \mathrm{t}_{\mathrm{t}}\right)$ [Trolox], where " $\mathrm{f}$ " is the dilution factor equal to the ratio of sample volume to the total volume of the solution. The measurements were repeated three times for each sample.

\section{Determination of antioxidant activity against DPPH}

Dried pomaces have been milled at the mill Fritsch puloerisette ${ }^{\circledR}$ (Idar-Oberstein, Germany) with a sieve diameter of $\varnothing 0.80 \mathrm{~mm}$ and then they were weighted for 6-10 $\mathrm{g}$ with an accuracy of $\pm 0.01 \mathrm{~g}$ and put into $250 \mathrm{~mL}$ Erlenmeyer Flasks with stopper. The extraction was done in two steps with $100 \mathrm{~mL}$ of eluent $(50+50)$ deionized water (at a temperature of $100^{\circ} \mathrm{C}$ and left for 5 minutes). After addition of the extraction reagent to the sample, the mixture was shaken for 15 minutes and then filtered through a $45 \mu \mathrm{m}$ nylon filter. The extracts were collected and then evaporated on a rotary evaporator R-200 Büchi (Flawil, Switzerland) at a bath temperature of $40^{\circ} \mathrm{C}$. The antioxidant activity of the flavonoid extracts was determined by the DPPH radical method according to the method described by Gow-Chin and Hui-Yin (1995).

The principle of the method consists in the reaction of DPPH with antioxidant ingredients which cause the reduction. The result of the reduction reaction is a change in color (from dark violet to light yellow). The measurement was performed on the Beckmann DU 640 (Fullerton, USA) spectrophotometer and the absorbance value was determined at a wavelength of $\lambda=515 \mathrm{~nm}$ at time 0 and after 30 minutes. Antioxidant activity expressed as a percentage of incubation, was calculated by the formula:

$$
\text { Inhibition } \%=[(\text { Aco }- \text { Aat }) / \text { Aco }] \cdot 100
$$

where:

Aco-absorbance of control sample at time 0;

Aat-absorbance of the sample measured after 30 minutes.

This assay was performed in triplicate. 


\section{Statistics}

Indications were performed in duplicate by making three measurements for each; the means and standard deviation (SD) were calculated.

\section{Results}

On the basis of chemical analysis the content of basic nutrients was determined. Total protein content in dried pomaces of apple, strawberry, black currant, chokeberry and carrot was $6.91 \%, 16.22 \%, 12.76 \%, 10.77 \%$ and $10.39 \%$, respectively. The level of crude fat in the tested pomaces was highest in strawberries and black currants (11.63 and $10.52 \%)$, followed by chokeberry, apple and carrot $(5.15,3.30$ and $1.77 \%$, respectively). The crude fiber content in the dried pomaces ranged from $20.18 \%$ for black currant pomaces to $35.81 \%$ for dried strawberries. A $2-4$ times lower level of fiber (8.8\%) was recorded in dried carrots (Table 1).

Table 1. Basic composition of pomaces from apples, strawberries, black currants, chokeberries and carrot

\begin{tabular}{l|ccc|c|c}
\hline \multicolumn{1}{c|}{ Item } & Apple & Strawberry & Black currant & Chokeberry & Carrot \\
\hline Dry matter (\%) & 88.94 & 90.95 & 89.21 & 90.21 & 90.48 \\
Crude ash (\%) & 1.48 & 3.69 & 3.49 & 1.95 & 6.94 \\
Total protein (\%) & 6.91 & 16.22 & 12.76 & 10.77 & 10.39 \\
Crude fat (\%) & 3.30 & 11.63 & 10.52 & 5.15 & 1.77 \\
Crude fiber (\%) & 25.69 & 35.81 & 20.18 & 21.79 & 8.8 \\
NDF (\%) & 42.07 & 45.41 & 38.81 & 34.65 & 12.07 \\
ADF (\%) & 34.27 & 40.7 & 34.36 & 35.59 & 11.87 \\
ADL $(\%)$ & 9.22 & 16.78 & 13.13 & 17.58 & 2.79 \\
Soluble sugars (\%) & 0.61 & 0.68 & 2.00 & 0.35 & 11.44 \\
Na $(\mathrm{g} / \mathrm{kg})$ & 0.018 & 0.038 & 0.036 & 0.037 & 3.65 \\
$\mathrm{~K}(\mathrm{~g} / \mathrm{kg})$ & 4.49 & 2.69 & 4.28 & 2.78 & 27.0 \\
$\mathrm{Ca}(\mathrm{g} / \mathrm{kg})$ & 1.50 & 3.55 & 3.32 & 2.75 & 3.39 \\
$\mathrm{P}(\mathrm{g} / \mathrm{kg})$ & 1.49 & 4.57 & 2.97 & 2.39 & 3.90 \\
$\mathrm{Mg}(\mathrm{g} / \mathrm{kg})$ & 0.45 & 1.27 & 0.85 & 0.88 & 1.2 \\
$\mathrm{Fe}(\mathrm{mg} / \mathrm{kg})$ & 91.8 & 371 & 244 & 197 & 22.3 \\
$\mathrm{Mn}(\mathrm{mg} / \mathrm{kg})$ & 8.75 & 48 & 18.9 & 31.5 & 13.1 \\
$\mathrm{Zn}(\mathrm{mg} / \mathrm{kg})$ & 6.90 & 25.9 & 17.4 & 15.7 & 28.4 \\
$\mathrm{Cu}(\mathrm{mg} / \mathrm{kg})$ & 1.36 & 8.56 & 7.99 & 1.95 & 4.24 \\
\hline
\end{tabular}

The detergent fiber fractions were also determined. The highest level of NDF fraction was found in dried pomaces made of apple and strawberry (42.07 and $45.41 \%)$, slightly lower in black currants $(38.81 \%)$ and chokeberry $(34.65 \%)$, and only $12.07 \%$ in dried carrot pomace. Similar relationships to the NDF fraction were noted in acid detergent fiber fraction (ADF). The highest level of lignin fractions (ADL) was found in the dried pomaces of chokeberry (17.58\%), slightly 
lower in the dried strawberry and black currant (16.78 and $13.13 \%)$ and apple pomaces $(9.22 \%)$. The lowest level of lignin was recorded in the dried carrot pomaces $(2.79 \%)$. The highest level of soluble sugars was found in dried carrot pomaces $(11.44 \%)$, followed by $2.0 \%$ in chokeberries, and only $0.3-0.6 \%$ in the others. Table 1 shows the results of analyses of macro- and microelements. Tested pomaces proved to be a good source of macrominerals, the levels of which were as follows: $\mathrm{Ca}-1.5-3.55 \mathrm{~g} / \mathrm{kg}$ of dried pomace, $\mathrm{P}-1.49-4.57 \mathrm{~g} / \mathrm{kg}, \mathrm{Mg}-0.45-1.20 \mathrm{~g} / \mathrm{kg}$, $\mathrm{Na}-0.018-3.650 \mathrm{~g} / \mathrm{kg}$ and $\mathrm{K}-2.69-27.0 \mathrm{~kg} / \mathrm{kg}$ of dried pomaces. Moreover, the pomaces contained considerable amounts of microelements such as: Fe (22.3$-371.0 \mathrm{mg} / \mathrm{kg}), \mathrm{Mn}(8.75-48.0 \mathrm{mg} / \mathrm{kg}), \mathrm{Zn}(6.9-28.4 \mathrm{mg} / \mathrm{kg})$ and $\mathrm{Cu}(1.36-8.56 \mathrm{mg} / \mathrm{kg}$ of dried pomaces).

Table 2. Amino acid content in dried pomaces from apples, strawberries, black currants, chokeberries and carrot (g/kg d.m.)

\begin{tabular}{lcc|c|c|c}
\hline \multicolumn{1}{c|}{ Amino acids } & Apple & Strawberry & Black currant & Chokeberry & Carrot \\
\hline Aspartic acid (asp) & 6.73 & 18.82 & 10.98 & 8.91 & 10.99 \\
Threonine (thr) & 2.79 & 5.37 & 4.81 & 2.98 & 2.56 \\
Serine (ser) & 2.77 & 5.87 & 4.85 & 3.68 & 2.41 \\
Glutamic acid (glu) & 8.50 & 24.03 & 18.34 & 19.79 & 19.81 \\
Proline (pro) & 2.54 & 5.18 & 6.60 & 3.24 & 1.98 \\
Glycine (gly) & 3.45 & 7.78 & 8.10 & 6.38 & 2.68 \\
Alanine (ala) & 3.19 & 6.93 & 5.55 & 4.10 & 4.03 \\
Valine (val) & 3.26 & 7.63 & 5.11 & 4.21 & 3.58 \\
Isoleucine (ile) & 2.90 & 6.80 & 6.39 & 3.78 & 2.83 \\
Leucine (leu) & 5.03 & 11.51 & 8.47 & 6.86 & 4.18 \\
Tyrosine (tyr) & 1.79 & 4.10 & 3.42 & 2.47 & 1.94 \\
Phenylalanine (phe) & 2.99 & 7.19 & 5.97 & 4.30 & 4.69 \\
Histidine (his) & 1.60 & 3.93 & 3.15 & 2.47 & 1.50 \\
Lysine (lys) & 3.66 & 6.61 & 6.51 & 3.67 & 2.55 \\
Arginine (arg) & 3.37 & 11.39 & 8.16 & 7.91 & 5.51 \\
Cysteine (cys) & 0.79 & 2.44 & 2.34 & 1.84 & 0.76 \\
Methionine (met) & 1.26 & 3.97 & 2.54 & 1.77 & 1.17 \\
Tryptophan (try) & 0.72 & 1.90 & 1.36 & 1.33 & 0.41 \\
Sum of essential amino acids & 22.61 & 50.98 & 40.16 & 28.90 & 21.97 \\
\hline
\end{tabular}

The total amino acid profile of dried pomaces was shown in Table 2. The most preferred amino acid profile was characteristic of the dried pomace from strawberries and black currants. Dried strawberries are rich in important amino acids especially from the point of view of animal feeding, among others lysine, methionine, cysteine, leucine, isoleucine, tyrosine, and tryptophan. In contrast, dried black currant pomaces were characterized by a high content of proline, lysine and cysteine. The highest content of essential amino acids was observed in strawberry - 50.98 (g/kg d.m.), followed by black currant (40.16), chokeberry (28.90), apple (22.61) and carrot (21.97 g/kg d.m.). 
The highest content of anthocyanins was detected in chokeberries (191.03 $\mathrm{mg} / 100 \mathrm{~g})$ and black currants $(113.78 \mathrm{mg} / 100 \mathrm{~g})$, and several times less in strawberries $(35.36 \mathrm{mg} / 100 \mathrm{~g})$, carrots $(4.32 \mathrm{mg} / 100 \mathrm{~g})$ and apples $(2.11 \mathrm{mg} / 100 \mathrm{~g})$ (Table 4). Carotenoids were detected only in the dried carrot pomaces in the amount of 15.35 $\mathrm{mg} / 100 \mathrm{~g}$ (Figure 1). Calculated from the HPLC analysis of the total content of carotenoids was composed of beta-carotene and lutein, while the rest were the total xanthophylls content. The highest level of $\alpha$-tocopherol was noted in the dried pomaces of chokeberry $(152.3 \mathrm{mg} / 100 \mathrm{~g})$, followed by black currant and strawberries (114.0 and $102.3 \mathrm{mg} / 100 \mathrm{~g}$ ). The lowest content of vitamin $\mathrm{E}$ was found in carrots and apples at 41.5 and $22.4 \mathrm{mg} / 100 \mathrm{~g}$, respectively (Table 6).

Table 3. The fatty acid composition in dried pomaces from apples, strawberries, black currants, chokeberries and carrot ( $\%$ of total fatty acids)

\begin{tabular}{|c|c|c|c|c|c|}
\hline Fatty acids & Apple & Strawberry & Black currant & Chokeberry & Carrot \\
\hline $\mathrm{C} 8: 0$ & 0.03 & 0.13 & 0.02 & 0.02 & 0.05 \\
\hline $\mathrm{C} 12: 0$ & 0.21 & 0.47 & 0.15 & 0.07 & 0.37 \\
\hline C14:0 & 0.27 & 0.42 & 0.47 & 0.12 & 0.33 \\
\hline $\mathrm{C} 16: 0$ & 15.75 & 13.71 & 12.11 & 5.48 & 8.60 \\
\hline $\mathrm{C} 16: 1$ & 0.24 & 0.33 & 0.36 & 0.19 & 0.24 \\
\hline $\mathrm{C} 18: 0$ & 1.25 & 4.66 & 1.66 & 1.71 & 1.98 \\
\hline $\mathrm{C} 18: 1$ & 5.37 & 17.36 & 10.47 & 16.38 & 17.42 \\
\hline C18:2 & 64.35 & 48.88 & 41.56 & 43.43 & 63.97 \\
\hline Gamma18:3 & 0.14 & 0.15 & 8.01 & 0.03 & 0.04 \\
\hline $\mathrm{C} 18: 3$ & 8.45 & 5.55 & 15.17 & 29.78 & 3.08 \\
\hline CLA c9-t11 & 0.00 & 0.00 & 0.00 & 0.01 & 0.00 \\
\hline C18:4 & 0.03 & 0.00 & 2.14 & 0.02 & 0.00 \\
\hline CLA c9-c11 & 0.00 & 0.00 & 0.03 & 0.00 & 0.03 \\
\hline $\mathrm{C} 20: 0$ & 1.14 & 3.65 & 2.37 & 1.52 & 1.68 \\
\hline $\mathrm{C} 20: 1$ & 0.26 & 0.47 & 0.76 & 0.33 & 0.30 \\
\hline $\mathrm{C} 20: 2$ & 0.28 & 0.31 & 0.38 & 0.14 & 0.19 \\
\hline $\mathrm{C} 20: 4$ & 0.00 & 0.00 & 0.00 & 0.00 & 0.00 \\
\hline C20:5 (EPA) & 0.00 & 0.05 & 0.00 & 0.00 & 0.01 \\
\hline $\mathrm{C} 22: 0$ & 1.78 & 3.03 & 2.55 & 0.59 & 1.31 \\
\hline $\mathrm{C} 22: 5$ & 0.41 & 0.72 & 1.81 & 0.17 & 0.39 \\
\hline C22:6 (DHA) & 0.05 & 0.11 & 0.01 & 0.00 & 0.00 \\
\hline SFA & 20.43 & 26.07 & 19.33 & 9.51 & 14.33 \\
\hline UFA & 79.57 & 73.93 & 80.67 & 90.49 & 85.67 \\
\hline PUFA $n-6$ & 64.76 & 49.34 & 49.94 & 43.60 & 64.20 \\
\hline PUFA $n-3$ & 8.94 & 6.44 & 19.12 & 29.97 & 3.47 \\
\hline PUFA $n-6 / n-3$ & 7.24 & 7.66 & 2.61 & 1.45 & 18.50 \\
\hline
\end{tabular}

The content of chosen phenolic acids (chlorogenic, caffeic and ellagic), determined in the studied fruit pomaces, ranged from $12.91 \mathrm{mg} / 100 \mathrm{~g}$ in black currants to $630.30 \mathrm{mg} / 100 \mathrm{~g}$ in dried chokeberries (Figure 2). 
Table 3 shows the results of the fatty acid composition. High level of crude fat in the analyzed samples of pomaces, exceeding $10 \%$ in the case of dried black currant and strawberry pomaces provides a rich source of fatty acids. The fatty acids composition of dried pomaces of apples, strawberries, black currants, chokeberries and carrot was characterized by a high content of unsaturated fatty acids (UFA): $79.57 \%$, $73.93 \%, 80.67 \%, 90.49 \%$ and $85.67 \%$, respectively.

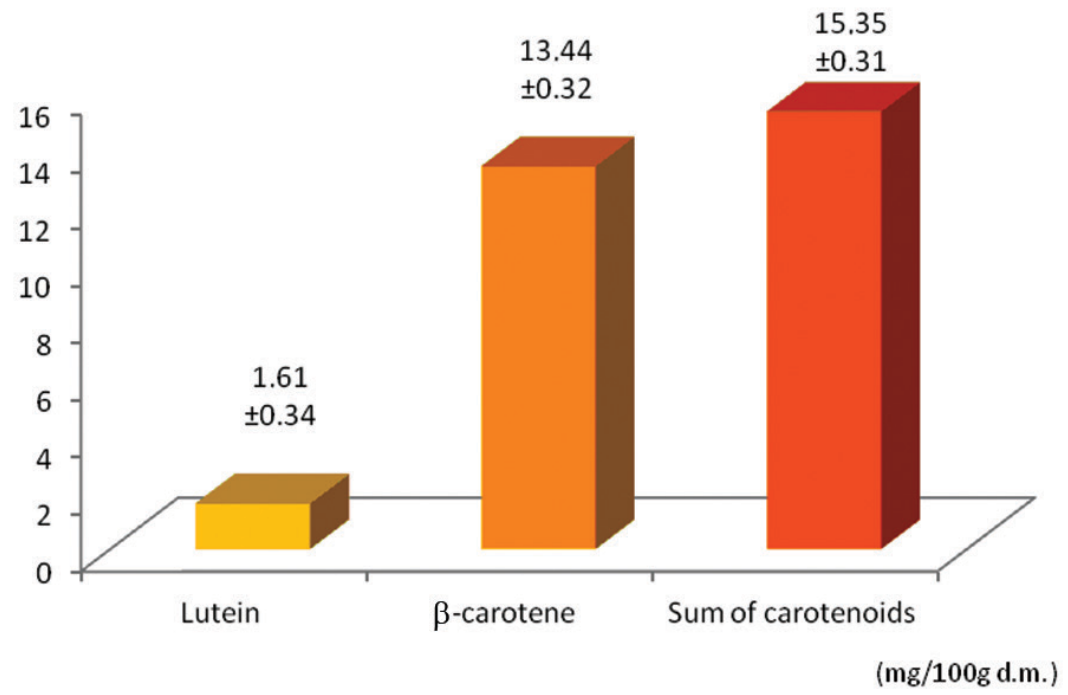

Figure 1. The results of HPLC analysis of lutein, $\beta$-carotene and sum of carotenoids in dried carrots (in $\mathrm{mg} / 100 \mathrm{~g}$ of d.m. of pomace; $\mathrm{SD} \pm \mathrm{n}=3$ )

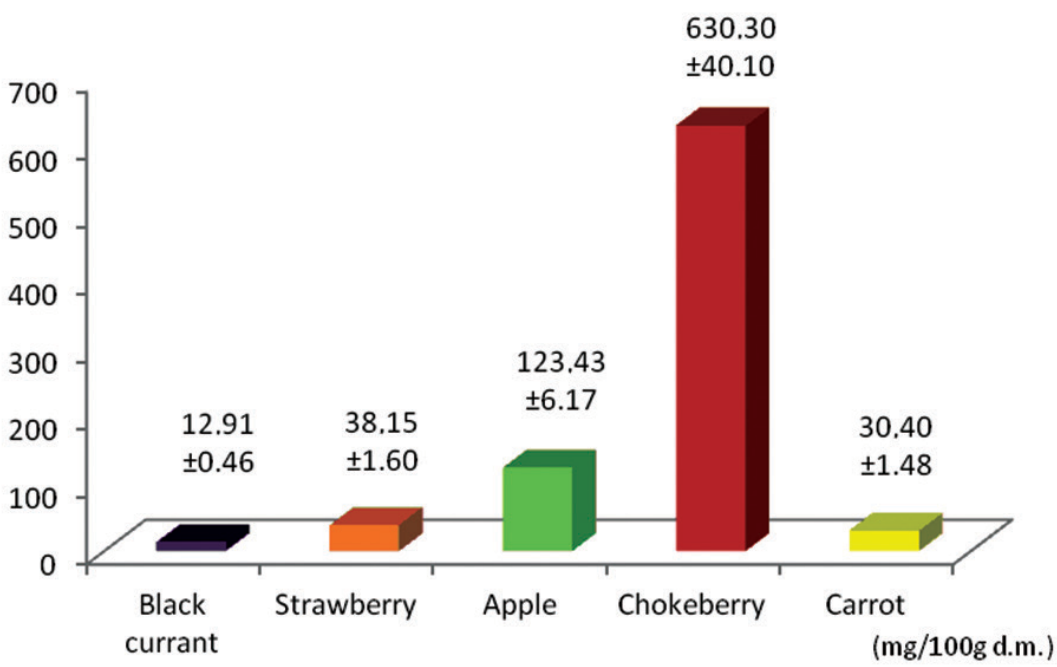

Figure 2. The concentration of chlorogenic, caffeic and ellagic acids based on the calculated chlorogenic acid (mg/100 g d.m.; $\mathrm{SD} \pm \mathrm{n}=3$ ) 
The highest differences in the fatty acid profile in the tested dried pomaces were observed for $\alpha$-linolenic and linoleic acids. Dried apple and carrot pomaces contained a high level of linoleic acid (C18:2): $64.35 \%$ and $63.97 \%$, respectively. The highest level of $\alpha$-linolenic acid $(\alpha \mathrm{C} 18: 3)$ was found in dried chokeberry and black currant $(29.78 \%$ and $15.17 \%)$. Dried black currant pomaces were the richest source of $\gamma$-linolenic acid $(\gamma \mathrm{C} 18: 3)$ and stearidonic acid $(\mathrm{C} 18: 4)$ at $8.01 \%$ and $2.14 \%$, respectively. In contrast, dried strawberry, chokeberry and carrot pomaces contained high levels of oleic acid (C18:1): 17.36\%, 16.38\% and 17.42\%, respectively. The lowest $n-6$ to $n$ - 3 PUFA ratio was found in dried chokeberries and black currants (1.45 and 2.61), compared to 7.24, 7.66 and 18.50 in dried apples, strawberries and carrots, respectively.

Table 4. The average content of anthocyanins in studied dried pomaces, calculated on the basis of spectrophotometric measurements in $\mathrm{mg} / 100 \mathrm{~g}$ of dry matter of pomace

\begin{tabular}{lcc}
\hline \multicolumn{1}{c|}{ Pomace type } & Sum of anthocyanins $(\mathrm{mg} / 100 \mathrm{~g} \mathrm{d.m} ; \mathrm{SD} \pm \mathrm{n}=3)$ \\
\hline Apple & $2.11 \pm 0.11$ \\
Strawberry & $35.36 \pm 1.87$ \\
Black currant & $113.78 \pm 4.55$ \\
Chokeberry & $191.03 \pm 8.78$ \\
Carrot & $4.32 \pm 0.31$ \\
\hline
\end{tabular}

Table 5. The antioxidant activity of aqueous extracts of dried pomaces from apples, strawberries, black currants, chokeberries and carrot against DPPH

\begin{tabular}{lcc}
\hline \multicolumn{1}{c|}{ Pomace type } & Antioxidant activity $(\% ; \mathrm{SD} \pm \mathrm{n}=3)$ \\
\hline Apple & $47.3 \pm 7.15$ \\
Strawberry & $39.3 \pm 1.03$ \\
Black currant & $68.2 \pm 4.90$ \\
Chokeberry & $67.0 \pm 2.15$ \\
Carrot & $37.7 \pm 6.69$ \\
\hline
\end{tabular}

Table 6. The content of $\alpha$-tocopherol in dried pomaces from apples, strawberries, chokeberries, black currants, apples and carrot (mg/100 g of dry matter of dried pomace) determined by HPLC

\begin{tabular}{lcc}
\hline \multicolumn{1}{c|}{ Pomace type } & $\alpha$-tocopherol level mg/100 g of pomace d.m., SD $\pm \mathrm{n}=3$ \\
\hline Apple & $22.4 \pm 0.78$ \\
Strawberry & $102.3 \pm 4.70$ \\
Black currant & $114.0 \pm 5.75$ \\
Chokeberry & $152.3 \pm 7.00$ \\
Carrot & $41.5 \pm 1.57$ \\
\hline
\end{tabular}

The antioxidant activity was determined using a binding assay of DPPH radical. The highest antioxidant activity was characteristic of black currant and chokeberry pomaces, the value of which amounted to $68.2 \%$ and $67.0 \%$, followed by the solution with the addition of apples, strawberries and carrot pomaces: $47.3 \%, 39.4 \%$ and $37.7 \%$, respectively (Table 5). 
The total antioxidant potential (TRAP) of aqueous extracts of dried pomace was measured by chemiluminescence expressed as Trolox equivalent. The highest antioxidant potential was characteristic of the solutions of chokeberry, apple and black currant pomaces at 179 and $82 \mu \mathrm{g}$ TE/g, respectively (Table 7). Two/three times lower antioxidant capacity was found in the solutions with strawberry and carrot pomaces (61 and $50 \mu \mathrm{g} \mathrm{TE} / \mathrm{g})$.

Table 7. The total antioxidant capacity (TRAP) of aqueous extracts of dried pomaces from apples, strawberries, chokeberries, black currants and carrot as measured by chemiluminescence

\begin{tabular}{l|c}
\hline \multicolumn{1}{c|}{ Pomace type } & $\begin{array}{c}\text { Antioxidant capacity (Trolox equivalent, } \\
\mu \mathrm{g} \mathrm{TE} / \mathrm{g} \text { pomace; SD } \pm \mathrm{n}=3 \text { ) }\end{array}$ \\
\hline Apple & $96 \pm 2.4$ \\
Strawberry & $61 \pm 1.52$ \\
Black currant & $82 \pm 1.88$ \\
Chokeberry & $179 \pm 3.93$ \\
Carrot & $50 \pm 1.05$ \\
\hline
\end{tabular}

\section{Discussion}

In recent years, much attention has been paid to issues related to the presence of natural and biologically active substances in food as well as in animal feed, which play a significant role in protecting against the damaging effects of free radicals. Among the many substances with antioxidant properties, vitamins A, C, E should be mentioned together with carotenoids and polyphenols. A rich source of these compounds are fruits and vegetables (Dewanto et al., 2002; Holden et al., 2002; Wu et al., 2001; Nawirska and Oszmański, 2001; Peschel et al., 2006; Kołodziejczyk et al., 2007; Nawirska et al., 2007).

In comparison to the nutrient content of bran, a by-product in the preparation of cereal flour, tested pomaces are characterized by a similar content of basic nutrients such as protein and fat (Tables of chemical composition of fodder, 2010). The chemical composition of dried fruit pomaces depends on the raw material from which we obtain it, and this in turn depends on the weather conditions, fertilization and agronomic treatments. The second important factor determining the quality of the dried material obtained is the process of drying, the type of dryer and drying parameters. Nutrients which are highly heat-sensitive are amino acids and vitamins and some of the pigments (Alasalvar et al., 2001).

The amino acid content limited in the studied fruit pomaces, among others, methionine, lysine and threonine, was higher than the levels of these amino acids in the wheat bran (Tables of chemical composition of fodder, 2010). However, considering the chemical composition of the fruit pomaces, it is necessary to note the large amount of free extracts, compared with the other components, in the form of sugars, organic acids, pectins, flavonoids and vitamins. 
The results confirm the effect of organic acids and phenolic acids contained in the pomaces made of berries and apples on palatability and feed intake (Taasoli and Kafilzadadeh, 2008). It is also necessary to pay attention to the high content of dietary fiber in fruit pomaces. Extensive research on the composition of dietary fiber in fruit pomaces was conducted by Nawirska and Kwaśniewska (2004), which showed a high content of hemicellulose and pectin in apple, chokeberry and black currant pomaces. Dietary fiber buffers and binds the excess of hydrochloric acid in the stomach, increases the filling of intestines, improves the tone of the intestinal walls and the overall condition of the mucous membranes of the gastrointestinal tract. Furthermore, the fiber passing through the gastrointestinal tract stimulates stomach cells to secrete digestive enzymes. It creates a preferred substrate for the desired development of the bacterial flora in the large intestine. The components of dietary fiber and especially pectins are capable of binding metal (Nawirska and Oszmański, 2001). Properties of dietary fiber also contribute to the mitigation of disturbances in digestion and intestinal inflammation, prevent diarrhea, improve intestine peristalsis and the passage of gastric contents. The peristalsis is necessary for the proper course of digestion and excretion.

Dried pomaces from chokeberries, apples, black currants, strawberries and carrots are characterized by a high content of neutral-detergent fiber (NDF), on average about $34.6 \%$. This fraction of low lignin is digested by microorganisms in the cecum and colon of monogastric animals and by rumen bacteria and protozoa in ruminants (Rumsey, 1978). During the fermentation process volatile fatty acids (butyric, acetic, propionic and other acids) are released which are used by adult animals with fully mature digestive tract (e.g. sows, boars, cows, horses). Volatile fatty acids (SCFA), mainly acetic, propionic and butyric acids are the main source of energy used for the synthesis of milk fat (Khiaosa-ard and Zebeli, 2014).

The fibrous fraction, especially in the case of pregnant sows improves satiety of animals. It also reduces the incidence of aggressive behavior, often improves the quality of the feces and reduces the tendency to constipation.

Fermentation of carbohydrates (dietary fiber), mainly soluble fiber (SDF) takes place in the large intestine with the participation of bacteria, yeast and protozoa. During transformation of the fiber short chained fatty acids (SCFA) including acetic, propionic and butyric acids are synthesized and released outside the cells. Especially butyric acid is often metabolized by intestinal mucosal cells by providing them with energy and improving mineral absorption (Bugaut, 1987). Short chained fatty acids have a positive impact on the epithelium of the colon and the regulation of cholesterol and triglyceride synthesis in the liver (Khiaosa-ard and Zebeli, 2014). It was documented that as a result of emerging biochemical abnormalities in gnotobiotic mice their daily energy demand increased by 30\% (Wostman et al., 1983).

While in dairy cows fiber is pre-digested in the rumen by protozoa and predigested fiber is processed by bacteria into metabolites absorbed into the blood through the mucosa of the rumen. In the case of excessive share of fodder with high concentration of energy and protein in the ration, and too low of fiber, the acidity of the rumen slowly begins to increase leading to disturbances in digestion, usually of a chronic course, defined as indigestion of rumen. This leads to the mass dying of protozoa, the 
biological balance of the rumen environment is seriously upset and as a result fiber is not digested. Dietary fiber derived from fruit pomace is a natural buffer, stabilizing rumen $\mathrm{pH}$, which prevents the proper metabolism in the rumen (Abdollahzadeh and Abdulkarimi, 2012).

Dried pomaces should be considered as a valuable feed also because of the significant mineral content. It should be noted when comparing to sugar beet pulp and wheat bran that they contain approximately 5 times less of calcium, which should be taken into account when balancing the rations. The advantage of using dried pomaces of apples, chokeberries, black currants, strawberries and especially carrot in the diets of breeding females is that they contain significant amounts of beta-carotene, vitamin $\mathrm{E}$, vitamin $\mathrm{C}$ and $\mathrm{B}$ vitamins (thiamine, riboflavin, and niacin), which is of great importance in the processes of fertilization and embryonic development of fetuses. However, the most valuable component present in the dried pomaces of fruit and vegetable are flavonoid pigments, which can be classified as fitobiotics. A particularly rich source of flavonoids are fruits of berry plants which was confirmed in a number of works (Holden et al., 2002; Bojarska et al., 2006; Nawirska et al., 2007).

The main flavonoid pigments present in chokeberries and black currants are anthocyanins. Anthocyanins are compounds with extremely low toxicity. They are very well soluble in water that is why they can easily penetrate into the cells. They also show clear anti-inflammatory and antioxidant effects (Ramirez-Tortosa et al., 2001; Lam et al., 2008). In many studies it was found that the anthocyanins and other flavonoids, and phenolic compounds contained in the chokeberries and black currants prevent the excess formation of free radicals that have a harmful effect in the body (Wang and Jiao, 2000), as confirmed by the results of this work. Antiradical capacity depends on the type and content of substances with antioxidant properties. The antioxidant activity of chokeberries and black currants appears to depend not only on the level of anthocyanins, but also correlates with the content of flavonoids and other phenols which are present in substantial amounts, which was confirmed in this study. For example, the antioxidant activity of the juice as well as preparations derived from chokeberries rich in anthocyanins, lies inter alia in the prevention of the formation of radicals and the chelation of metals, as well as in catching already formed in excess free radicals and formation of less active compounds subjected to catalyzing the dismutation of transition process of radicals into inert materials (Wu et al., 2004; Lam et al., 2008). The harmful effects of aforementioned radicals released in excess include collagen degradation, inactivation of certain enzymes, DNA damage and generation of strand mutations, peroxidation of lipids of cell membranes and others. Chokeberry due to the presence of strong antioxidant compounds may inhibit inflammation processes in the mucosa of the intestine. This is due to the promotion of intestinal microflora normalization, exclusion of pathogens, reducing the permeability of the intestinal barrier and enhancing the immune response. In studies conducted by Tanaka and Yuda (1996) and Valcheva-Kuzmanova et al. (2005) chokeberry fruits acted protectively on the gastric mucosa. Matsumoto et al. (2004) pay particular attention to anthocyanins present in chokeberries, which have strong antiinflammatory and antioxidant activity, assigning precisely gastroprotective properties to this compound. Increased concentrations of butyric acid, which is an energy 
source for epithelial cells of the gastrointestinal tract were also observed (Valcheva-Kuzmanova et al. 2005; Petko et al., 2012).

Flavonoids are readily absorbed from the gastrointestinal tract, and some of them interact like vitamin $\mathrm{C}$ in the cytosolic phase of the cell. However, it is believed that the effect is more specific for certain important metabolic pathways. In studies on rats, administration of polyphenols in the diets affects the recovery of $\alpha$-tocopherol by reducing $\alpha$-tocopherol-radicals formation (Frank et al., 2006). Beecher (2003) in his concept has proposed alternative strategies of administration of very high doses of vitamin $\mathrm{E}$ in exchange for providing dietary flavonoids. An important flavonoid occurring inter alia in apples is quercetin; it seals blood vessels and has detoxicating, anti-inflammatory, diuretic and anti-allergenic effects (Liu et al., 2014). A somewhat smaller effect is shown by quercetin-related flavonol - kaempferol. Flavonoids retard the growth of atherosclerosis in blood vessels by lowering plasma cholesterol levels. The presence of quercetin has a very positive effect on the cardiovascular system, because it protects blood vessels from the settling of plaques and seals them. So, such a common fruit as apples can greatly protect against atherosclerosis and coronary heart disease. With quercetin they also exhibit anti-tumor and blood pressure lowering activities. The presence of flavonoid compounds can be explained by the healing properties of apples (Gazalli et al., 2014). Kaempferol, quercetin and rutin exhibit very strong antibacterial activity with respect to $\mathrm{Gram}^{+}$and $\mathrm{Gram}^{-}$pathogenic bacteria including Escherichia coli, Enterobacter aerogenes (Alvarez et al., 2007). Therefore, the presence of antibacterial substance in the diet of growing animals aimed at stimulating the intestinal microflora and proper development of intestinal microvilli is indispensable. Scientific reports have documented antiviral activity of the extract of black currant (Ribes nigrum) against influenza A and B by inhibiting the viral entry into cells. The mechanism of antiviral activity is based on anthocyanin penetration into the cell membranes of leukocytes which, in turn, penetrates into the cells attacked by the virus and further inhibits viral replication protein (Knox et al., 2001).

Analysis of the composition of higher fatty acids in dried pomaces of apples, chokeberries, black currants and strawberries showed that the tested pomaces are a good source of essential fatty acids. One of the ways of enriching the meat in polyunsaturated fatty acids (PUFA) is supplying the animal diets with these pomaces. A feeding trial conducted on rabbits has shown the effect of adding dried tomato pomaces on the change of fatty acid profile of the meat, an increase in the level of PUFAs was also observed, especially $n-3$ which are beneficial for human health (Peiretti et al., 2013).

One of the main ways to enrich meat in polyunsaturated fatty acids (PUFA) are oils and oilseeds added to the diet of pigs, cattle and poultry (Scolan et al., 2001; Smink et al., 2010; Skiba et al., 2011). Similar modifications in the fatty acid composition can be achieved in milk and eggs (Rego et al., 2005; Oliveira et al., 2010).

The limitation, especially in the nutrition of broiler chickens, seems to be the level of crude fiber in pomaces. However, due to the high content of active substances and taking into account the level of crude fiber in the ration, it seems interesting from the scientific and practical point of view to use the tested pomaces in ruminant nutrition, selected groups of monogastric animal species and ecological farming of 
poultry. Rich in dietary fibers, especially in pectins, dried currant and apple pomaces are an appropriate component of compound feeds for animals which require a limited demand for protein and energy; in the case of feeding low-in-pig sows they play a major physiological role in the proper course of pregnancy and lactation (Vestergaard and Danielsen, 1998). Enriching the diet of animals in natural supplements rich in the above mentioned substances can improve the palatability of feed, and thus increase feed intake and improve feed utilization by animals.

\section{Conclusions}

On the basis of results of this work concerning chemical analysis of pomaces from apples, black currants, chokeberries, strawberries and carrot it can be concluded that the dried pomaces are a very valuable component of feed rations for animals. The high content of desirable bioactive substances such as vitamins, anthocyanins and phenolic acids causes the high antioxidative activity. The studied pomaces are a valuable source of polyunsaturated fatty acids and vitamins which may affect the enrichment of the tissues of animals in natural compounds and this should improve the quality and value of food products derived from such animals. Moreover, dietary fiber contained in the pomaces improves the health status of digestive tract.

However, their impact on certain species of animals representing different production types or physiological states requires further research.

\section{References}

Abdollahzadeh F., Abdulkarimi R. (2012). The effects of some agricultural by-products on ruminal fermentation and apparent digestibility of Holstein dairy cows. Life Sci. J., 9: 81-85.

A las a lvar C., Grigor J.M., Zhang D., Quantick P.C., Shahidi F. (2001). Comparison of volatiles, phenolics, sugars, antioxidant vitamins, and sensory quality of different colored carrot varieties. J. Agric. Food Chem., 49: 1410-1416.

A lvare z M.A., D e bat t is t a N.B., P a p p a no N.B. (2007). Antimicrobial activity and synergism of some substituted flavonoids. Folia Microbiol., 53: 23-28.

AOAC (1995). Association of Official Analytical Chemists. Official Methods of Analysis, 16th ed., Arlington, Virginia, USA.

B e echer G.R. (2003). Overview of dietary flavonoids: nomenclature and intake. J. Nutr., 13: 3248-3254.

B oj ar sk a J.E., C z a pli cki S., Z a re cka K., Z a d ernow ski R. (2006). Phenolic compounds in selected varieties of strawberry fruit (in Polish). Food Sci. Technol. Quality Suppl., 2: 20-27.

B u g a u t M. (1987). Occurrence, absorption and metabolism of short chain fatty acids in the digestive tract of mammals. Comp. Biochem. Physiol., 86: 439-472.

D e w a n to V., W u X, A d o m K.K., Li u R.H. (2002). Thermal processing enhances the nutritional value of tomatoes by increasing total antioxidant activity. J. Agric. Food Chem., 50: 3010-3014.

F ol ch J., L e e s M., S t a n le y G.H.S. (1957). A simple method for the isolation and purification of total lipids from animal tissues. J. Biol. Chem., 226: 497-509.

Frank J., Budek A., Lundh T., P arker R.S., S w an so n J.E., La urenco C.F., Gago B. Laranjinha J., Vessby B., Kamal-Eldin A. (2006). Dietary flavonoids with a catechol structure increase $\alpha$-tocopherol in rats and protect the vitamin from oxidation in vitro. J. Lipid Res., 47: $2718-2725$.

Gazalli H., Malik A.H., S ofi A.H., Wani S.A., Pal M.P., A shraf H. (2014). Nutritional value and physiological effect of apple pomace. Int. J. Food Nutr. Safety, 5: 11-15. 
Go er ing H.K., Van S o e s t P.J. (1970). Forage fiber analysis. Department of Agriculture. Handbook 379. Washington, DC, pp. 1-20.

G ow - Ch in Y., Hu i - Y in C. (1995). Antioxidant activity of various tea extracts in relation to their antimutagenicity. J. Agric. Food Chem., 43: 27-32.

Graversen H.B., B e c k e r E.B., S k i b s ted L.H., A n d e r s e n M.L. (2008). Antioxidant synergism between fruit juice and alpha-tocopherol. A comparison between high phenolic black chokeberry (Aronia melanocarpa) and high ascorbic blackcurrant (Ribes nigrum). Eur. Food Res. Technol., 226: 737-743.

H o ld e n J.M., B ha g w a t S., P a t $t$ e r s o n K.Y. (2002). Development of a multi-nutrient data quality evaluation system. J. Food Comp. Anal., 15: 339-348.

K hi a o s a - ard R., Z e beli Q. (2014). Cattle's variation in rumen ecology and metabolism and its contributions to feed efficiency. Livestock Sci., 162: 66-75.

Knox Y.M., Hay a shi K., Suzutani T., Ogas aw a ra M., Yoshida I., Shi ina R., Tsuku i A., Ter ahar a N., A z u m a M. (2001). Activity of anthocyanins from fruit extract of Ribes nigrum L. against influenza A and B viruses. Acta Virol., 45: 209-215.

Kołodziejczyk K., Markowski J., Kosmala M., Król B., Płocharski W. (2007). Apple pomace as potential source of nutraceutical products. Pol. J. Food Nutr. Sci., 57: 291-295.

Lam C.K., Zhang Z., Yu H., Tsang S.Y., Huang Y., Chen Z.Y. (2008). Apple polyphenols inhibit plasma CETP activity and reduce the ratio of non-HDL to HDL cholesterol. Mol. Nutr. Food Res., 52: 950-958.

L i s s i E., S a 1 i m-Hanna M., P a s c u a 1 C., C a s t 111 o M.D. (1995). Evaluation of total antioxidant reactivity from luminol-enhanced chemiluminescence measurement. Free Rad. Biol. Med., 2: $153-158$.

L i u H., G u o X., C h u Y., L u S. (2014). Heart protective effects and mechanism of quercetin preconditioning on anti-myocardial ischemia reperfusion (IR) injuries in rats. Gene, 545: 149-155.

Mats u moto M., Har a H., Chij i H., K a s a i T. (2004). Gastroprotective effect of red pigments in black chokeberry fruit (Aronia melanocarpa Elliot) on acute gastric hemorrhagic lesions in rats. J. Agric. Food Chem., 52: 2226-2229.

Mech-Nowak A., Świderski A., Kruczek M., Luczak I., Kostecka-Gugała A. (2012). Content of carotenoids in roots of seventeen cultivars of Daucus carota L. Acta Biochim. Pol., 59: 139-141.

N aw irs ka A., K w a śn i ew ska M. (2004). Fiber fractions from fruit in pomace (in Polish). Acta Sci. Pol. Technol. Aliment., 3: 13-20.

N a w irs k a A., O s z mańs ki J. (2001). The binding of metal ions by selected fractions of the substances contained in pomace of fruit (in Polish). Food Sci. Technol. Quality, 4: 66-77.

N a w irska A., S o kó ł - Łę t ow s k a A., K u chars ka A.Z. (2007). Antioxidant characteristics of pomace from different fruits (in Polish). Food Sci. Technol. Quality, 4: 120-125.

$\mathrm{N}$ o s e c k a B. (2005). Fruit and vegetable processing. Information for processors (in Polish). In: Polish village in Europe. Fruit \& Vegetables Industry. Cooperation Fund. Office of Rural Programs, April 2005, Warsaw.

O live ir a D.D., B a iã o N.C., C a n c a do S.V., Grinaldi R., S o u za M.R., L a r a L.J.C., L a n a A.M.Q. (2010). Effects of lipid sources in the diet of laying hens on the fatty acid profiles of egg yolks. Poultry Sci., 89: 2484-2490.

P e ir ett i P.G., Ga i F., B rug i a p a g li a A., G a s c o L. (2013). Effects of tomato pomace supplementation on carcass characteristics and meat quality of fattening rabbits. Meat Sci., 95: 345-351.

Pes chel W., Sánchez-R abaneda F., D i e k mann W., P l e s c her A., Gartiza I., Ji m é nez D., Lamuela-Ravetós R., Buxaderas S., Codina C. (2006). An industrial approach from vegetables and fruit wastes. Food Chem., 97: 137-150.

P e t ko N., D e nev C.G., Kratchanov G., Ciz M., L oje k A., K r a t chanova M.G. (2012). Bioavailability and antioxidant activity of black chokeberry (Aronia melanocarpa) polyphenols: in vitro and in vivo evidences and possible mechanisms of action. Food Sci. Food Safety, 11: $471-489$.

R a mirez-Tortos a C., Anders en O., Gardner P. (2001). Anthocyanin-rich extract decreases indices of lipid peroxidation and DNA damage in vitamin E depleted rats. Free Radic. Biol. Med., 31: 1033-1037. 
Rego O.A., Ros a H.J.D., Portugal P.V., Franco T.. Vouzela C.M., Borba A.E.S., B e s s a R.J.B. (2005). The effects of supplementation with sunflower and soybean oils on the fatty acid profile of milk fat from grazing dairy cows. Anim. Res., 54: 17-24.

Rum s e y T.S. (1978). Ruminal fermentation products and plasma ammonia of fistulated steers fed apple pomace-urea diets. J. Anim. Sci., 47: 967-976

S chieber A., Keller P., Carle R. (2001). Determination of phenolic acids and flavonoids of apple and pear by high-performance liquid chromatography. J. Chromatography A, 910: 265-273

S colla n N.D., Cho i N.J., K u r t E., F is her A.V., En s e r M., Wo od J.D. (2001). Manipulating the fatty acid composition of muscle and adipose tissue in beef cattle. Brit. J. Nutr., 85: 115-124.

Skiba G., Poławs ka E., Raj S., Weremko D., Czauderna M., Wojtasik M. (2011). The influence of dietary fatty acids on their metabolism in liver and subcutaneous fat in growing pigs. J. Anim. Feed Sci., 20: 379-388.

S mink W., Gerrits W.J.J., Hovenier R., Geelen M.J.W., Verstegen M.W.A., B eyn e n A.C. (2010). Effect of dietary fat sources on fatty acid deposition and lipid metabolism in broiler chickens. Poultry Sci., 89: 2432-2440.

Ś w i d e r s k i A., M u r a s P., K oł o c z e k H. (2004). Flavonoid composition in frost-resistant Rhododendron cultivars grown in Poland. Sci. Hortic., 100: 139-151.

Ta a s oli G., K a fil za da d e h F. (2008). Effect of dried and ensiled apple pomace from puree making on performance of finishing lambs. Pakistan J. Biol. Sci., 11: 294-297.

Tan a ka J., Yud a Y. (1996). Lipid peroxidation in gastric mucosal lesions induced by indomethacin in rat. Biol. Pharmacol. Bull., 19: 716-720.

Valcheva-Kuzmanova S., Marazova K., Krasnaliev I., Galunska B., Borisov a P., B e l c he v a A. (2005). Effect of Aronia melanocarpa fruit juice on indomethacin-induced gastric mucosal damage and oxidative stress in rats. Experim. Toxicol. Pathology, 56: 385-392.

Vestergaard E.M., Daniels en V. (1998). Dietary fibre for sows: effect of large amounts of soluble and insoluble fibres in the pregnancy period on the performance of sows during three reproductive cycles. Anim. Sci., 68: 355-362.

Wang S., Ji a o H. (2000). Scavenging of berry crops on superoxide radicals, hydrogen peroxide, hydroxyl radicals, and singlet oxygen. J. Agric. Food Chem., 48: 5677-5684.

Wos t mann B.S., L arkin C., Moriart y A., B ru c kn er - K a rdos s E. (1983). Dietary intake, energy metabolism, and excretory losses of adult male germfree Wistar rats. J. Amer. Assoc. Lab. Anim. Sci., 33: 46-50.

W u X., G u L., Pri o r R.L., M c K a y S. (2004). Characterization of anthocyanins and proanthocyanidins in some cultivars of Ribes, Aronia, and Sambucus and their antioxidant capacity. J. Agric. Food Chem., 52: 7846-7856.

Received: 15 IV 2014

Accepted: 25 VIII 2014 